\title{
Cytotoxicity and genotoxicity induced by coal and coal fly ash particles samples in V79 cells
}

León Mejía, G.; Silva, L.F.O.; Civeira, M.S.; Oliveira, M.L.S.; Machado, M.e; Villela, I.V.; Hartmann, A.;

Premoli, S.; Corrêa, D.S.; Da Silva, J.; Henriques, J.A.P.

\begin{abstract}
Exposure to coal and coal ashes can cause harmful effects in in vitro and in vivo systems, mainly by the induction of oxidative damage. The aim of this work was to assess cytotoxic and genotoxic effects using the V79 cell line treated with coal and coal fly ash particles derived from a coal power plant located in Santa Catarina, Brazil. Two coal samples (COAL11 and COAL16) and two coal fly ash samples (CFA11 and CFA16) were included in this study. COAL16 was co-firing with a mixture of fuel oil and diesel oil. The comet assay data showed that exposure of V79 cells to coal and coal fly ash particles induced primary DNA lesions. Application of lesion-specific endonucleases (FPG and ENDO III) demonstrated increased DNA effects indicating the presence of high amounts of oxidative DNA lesions. The cytokinesis-block micronucleus cytome assay analysis showed that exposure of V79 cells to high concentrations of coal and coal fly ash particles induced cytotoxic effects (apoptosis and necrosis) and chromosomal instability (nucleoplasmic bridges, nuclear buds, and micronucleus (MN) formation). These results may be associated with compounds contained in the surface of the particles as hazardous elements, ultrafine/nanoparticles, and polycyclic aromatic hydrocarbons (PAHs) which were detected in the samples.
\end{abstract}

\section{Keywords}

Coal; Coal fly ashes; DNA oxidative damage; Comet assay; Micronucleus assay 